\title{
Hubungan antara Karakteristik Klinis Pasien Mola Hidatidosa dengan Performa Reproduksi Pascaevakuasi di Rumah Sakit Hasan Sadikin Bandung
}

\author{
Vanessa Natasha Harjito ${ }^{1}$, Yudi Mulyana Hidayat ${ }^{2}$, Indah Amelia ${ }^{3}$ \\ ${ }^{1}$ Fakultas Kedokteran, Universitas Padjadjaran, \\ ${ }^{2}$ Departemen Ilmu Kebidanan dan Penyakit Kandungan, Fakultas Kedokteran Universitas Padjadjaran/RSUP \\ Dr. Hasan Sadikin, Bandung, Indonesia \\ ${ }^{3}$ Departemen Ilmu Kesehatan Masyrakat, Fakultas Kedokteran Universitas Padjadjaran
}

\begin{abstract}
Abstrak
Pada penderita mola hidatidosa terdapat beberapa karakteristik klinis yang dapat memengaruhi performa reproduksi, yaitu gambaran histopatologi proliferasi berlebih, besar uterus $\geq 20$ minggu, kadar $\beta$ - $\mathrm{hCG}>100.000$ $\mathrm{mIU} / \mathrm{mL}$, dan kista lutein praevakuasi. Banyak penderita mola hidatidosa merasa khawatir kondisinya dapat memengaruhi fungsi reproduksinya di kemudian hari. Penelitian ini bertujuan untuk mengetahui hubungan antara karakteristik klinis pasien mola hidatidosa dengan luaran kehamilan pascaevakuasi di Rumah Sakit Hasan Sadikin Bandung. Penelitan analitik komparatif ini menggunakan desain kohort retrospektif. Subjek penelitian adalah penderita mola hidatidosa di Rumah Sakit Hasan Sadikin Bandung pada periode 1 Januari 2010-31 Desember 2015 yang memenuhi kriteria penerimaan penelitian. Penelitian mencari hubungan antara variabel karakteristik klinis risiko tinggi (gambaran histopatologi proliferasi berlebih, besar uterus, kista lutein, dan kadar $\beta$-hCG) dengan variabel luaran kehamilan pascaevakuasi. Analisis data menggunakan uji Eksak Fisher dengan interval kepercayaan 95\%. Subjek penelitian berjumlah 51orang, terdapat 28 orang berkarakteristik klinis risiko tinggi. Hasil penelitian menunjukkan karakteristik klinis dan luaran kehamilan pada tipe mola komplit dan mola parsial tidak memiliki perbedaan signifikan $(p>0,05)$. Tidak terdapat hubungan yang signifikan antara gambaran histopatologi proliferasi berlebih, besar uterus, kista lutein, dan kadar $\beta$-hCG dengan luaran kehamilan pascaevakuasi( $\mathrm{p}>0,05)$. Penelitian ini menyimpulkan tidak terdapat hubungan antara karakteristik klinis pasien mola hidatidosa dengan performa reproduksi pascaevakuasi di Rumah Sakit Hasan Sadikin Bandung.
\end{abstract}

Kata Kunci : Karakteristik klinis risiko rendah, Karakteristik klinis risiko tinggi, Luaran kehamilan, Mola hidatidosa

\section{Relationship between Clinical Characteristics of Mole Hydatidiform Patient with Reproductive Performance Post-Evacuation in Hasan Sadikin General Hospital Bandung}

\begin{abstract}
In mole hydatidiform patients there are some clinical characteristics that could affect reproductive performance: hyperproliferation histopathologic finding, uterus size $\geq 20$ weeks, $\beta-h C G>100.000 \mathrm{mIU} / \mathrm{mL}$, and presence of theca lutein cyst pre-evacuation. Many patients are concerned that their conditions would affect their reproductive function in the future. This study aims to find out the relationship between clinical characteristics of mole hydatidiform patient with pregnancy outcome post evacuation in Hasan Sadikin General Hospital Bandung.A comparative analytic study was conducted using historical cohort study design. Study subjects were mole hydatidiform patients in Hasan Sadikin General Hospital Bandung during 1 January 2010-31 December 2015 that meet inclusion criteria. The study searched for the relationship between high risk clinical characteristics variable (hyperproliferation histopathologic finding, uterus size, $\beta-h C G$ level, and presence of theca lutein cyst) with post-mole evacuation pregnancy outcome variable. Exact Fisher Test was used for data analysis with confidence interval 95\%. Subject study comprised of 51 person, 28 of which have at least one high risk clinical characteristic. Research results showed that clinical characteristics and pregnancy outcome of complete and partial mole did not show a significant difference $(p>0,05)$. There was no significant relationship between hyperproliferation histopathologic finding, uterus size, $\beta-h C G$ level, and presence of lutein cyst with post-mole evacuation pregnancy outcome $(p>0,05)$. This research concluded there is no relationship between clinical characteristics of mole hydatidiform patient with reproductive performance post-evacuation in Hasan Sadikin General Hospital Bandung.
\end{abstract}

Keywords : Hydatidiform mole, High risk clinical characteristics, Low risk clinical characteristics, Pregnancy outcome

Korespondensi:

Vanessa Natasha Harjito

Fakultas Kedokteran, Universitas Padjadjaran

Jl. Raya Bandung-Sumedang km 21 Jatinangor

Mobile : 081572517530

Email : vanessa.natasha31@gmail.com 


\section{Pendahuluan}

Mola hidatidosa, lebih umum dikenal dengan sebutan hamil anggur, adalah kehamilan yang ditandai dengan perkembangan trofoblas yang tidak wajar. Pada mola hidatidosa, struktur yang dibentuk trofoblas yaitu vili korialis berbentuk gelembung - gelembung seperti anggur. ${ }^{1}$

Berdasarkan perbedaan genetik dan patologi, mola hidatidosa bisa dibagi menjadi dua subtipe yaitu, mola hidatidosa komplit dan parsial. ${ }^{2}$ Dibandingkan dengan penyakit trofoblas gestasional lainnya, mola hidatidosa merupakan tipe yang paling umum terjadi. ${ }^{3}$ Secara umum insidensi mola hidatidosa di Asia dan di Amerika Latin lebih tinggi bila dibandingkan dengan negara barat. Insidensi di Eropa dan Amerika Serikat adalah 1-2 per 1000 kehamilan, sedangkan insidensi di Asia Tenggara delapan kali lebih tinggi. ${ }^{1,3,4}$ Insidensi mola hidatidosa yang terdata di rumah sakit Indonesia lebih tinggi dari nilai di negara-negara lain, yaitu 1 per 40 persalinan. ${ }^{5}$, ${ }^{6} \mathrm{Hal}$ ini menunjukkan bahwa mola hidatidosa merupakan penyakit yang penting di Indonesia.

Banyak penderita mola hidatidosa merasa khawatir kondisinya dapat memengaruhi kesehatan reproduksinya. ${ }^{7}$ Beberapa penelitian menemukan bahwa seorang penderita mola hidatidosa, terutama yang bertipe mola komplit, memiliki risiko pengulangan mola 10-20 kali lipat lebih besar daripada populasi biasa. ${ }^{8-10}$ Disimpulkan pula bahwa $2 \%$ penderita mola hidatidosa dapat memperoleh kehamilan tidak normal pascaevakuasi. ${ }^{11}$ Untuk meningkatkan kesehatan reproduksi pascaevakuasi, maka perlu diketahui faktor-faktor yang memiliki hubungan dengan performa reproduksi pasien. Pada penderita mola hidatidosa terdapat beberapa karakteristik klinis yang dapat menunjukkan adanya risiko tinggi munculnya keganasan dan memengaruhi performa reproduksi. Salah satunya adalah peningkatan kadar $\beta-\mathrm{hCG}$, kondisi yang dapat mengganggu sistem hipotalamus-hipofisisovarium sehingga mungkin bisa menghasilkan luaran kehamilan yang berbeda. Gejala klinis ini berhubungan dengan adanya proliferasi sel sinsitiotrofoblas berlebih, karakteristik risiko tinggi yang dapat diamati pada gambaran histopatologi dan memiliki efek sekunder ukuran uterus melebihi umur kehamilan. Peningkatan kadar $\beta$-hCG dalam waktu yang lama dapat menimbulkan karakteristik risiko tinggi lainnya pula yaitu terdapat kista lutein pada ovarium. ${ }^{12-14}$

Perbedaan insidensi dan performa reproduksi mola hidatidosa dipengaruhi oleh beberapa faktor yang berbeda-beda di tiap lokasi, sehingga harus dilakukan penelitian secara lokal untuk mengetahuinya. ${ }^{15}$ Penelitian ini bertujuan untuk mengetahui hubungan antara karakteristik klinis pasien mola hidatidosa dengan performa reproduksi pascaevakuasi di Rumah Sakit Hasan Sadikin Bandung. Diharapkan hasil dari penelitian ini bisa memberi gambaran mengenai hubungan kehamilan mola hidatidosa terhadap fungsi reproduksi penderita dan bisa dijadikan tambahan penelitian selanjutnya. Selain itu, Rumah Sakit Hasan Sadikin merupakan salah satu rumah sakit rujukan nasional sehingga diharapkan hasil penelitian ini dapat merepresentasikan kondisi yang terdapat di Indonesia.

\section{Metode}

Penelitian ini dilakukan pada bulan Agustus 2016 hingga November 2016 di Departemen Obstetri dan Ginekologi Rumah Sakit Hasan Sadikin Bandung menggunakan studi desain kohort retrospektif. Penelitian ini merupakan penelitian analitik komparatif dengan skala pengukuran nominal kategorik.

Subjek penelitian merupakan seluruh pasien mola hidatidosa yang dirawat di Rumah Sakit Hasan Sadikin Bandung pada periode 1 Januari 2010 - 31 Desember 2015 RSUP Dr. Hasan Sadikin dengan kriteria inklusi berupa rentang usia 20-35 tahun: Telah menjalani evakuasi jaringan mola 1 tahun atau lebih sebelum pengambilan data, Rentang indeks massa tubuh 18,5 - 23, Tidak merokok, Masih menginginkan kehamilan pascaevakuasi mola hidatidosa, Data pada rekam medis lengkap.

Kriteria eksklusipada penelitian ini antara lain: Riwayat infertilitas sebelum evakuasi jaringan mola, Penderita mola hidatidosa yang dikelola dengan operasi histerektomi ataumendapat kemoterapi profilaksis, Penderita tidak bersedia menjadi subjek penelitian. Jumlah minimal sampel yang dibutuhkan pada penelitian ini sebanyak 80 orang, ditentukan berdasarkan rumus penelitian analitis kategorik tidak berpasangan. Sampel penelitian diambil menggunakan metode total sampling dikarenakan jumlah subjek yang memenuhi kriteria inklusi tidak mencapai jumlah minimal yang dibutuhkan. Jumlah subjek yang diikutsertakan dalam penelitian ini berjumlah 51 orang.

Data diambil dari rekam medis rawat jalan dan rawat inap setelah terlebih dahulu memperoleh surat etik dan surat izin penelitian. Data kemudian diseleksi berdasarkan kriteria inklusi dan eksklusi. Selanjutnya dilakukan kunjungan ke rumah pasien menggunakan alamat yang tertera pada rekam medis dan dilakukan informed consent. Pasien yang bersedia diikutsertakan dalam penelitian kemudian diwawancara secara 
langsung ataupun via telepon untuk mengetahui performa reproduksinya. Pasien yang tidak dapat dihubungi atau tidak dapat dikunjungi dieksklusi dari penelitian. Variabel independen pada penelitian ini adalah karakteristik klinis pasien mola hidatidosa yang meliputi: besar uterus, kista lutein, gambaran histopatologi, dan kadar $\beta$-hCG, sedangkan variabel dependen merupakan luaran kehamilan. Instrumen penelitian ini adalah rekam medis pasien rawat jalan dan rawat inap di Rumah Sakit Hasan Sadikin Bandung dan formulir untuk mengumpulkan data performa reproduksi pasien.

Setelah data terkumpul akan dilakukan pengolahan data menggunakan perangkat lunak Statistical Product and Service Solutions (SPSS) for Windows versi 24. Pasien dikelompokkan berdasarkan karakteristik klinis yang dimiliki, pasien yang memiliki salah satu karakteristik berikut: besar uterus $\geq 20$ minggu, terdapat kista lutein, gambaran histopatologi proliferasi berlebih, dan kadar $\beta$-hCG $>100.000 \mathrm{mIU} /$ $\mathrm{mL}$ akan dimasukkan ke dalam kelompok karakteristik klinis risiko tinggi, sedangkan sisanya dimasukkan ke dalam kelompok karakteristik klinis risiko rendah. Karakteristik pasien meliputi; usia, indeks massa tubuh (IMT), paritas, dan tipe mola dianalisis terlebih dahulu menggunakan uji statistik yang sesuai untuk memastikan bahwa karakteristik pasien tidak memiliki perbedaan yang bermakna sehingga layak untuk dibandingkan. Selanjutnya dilakukan analisis tabulasi silang pada karakteristik klinis dan luaran kehamilan pascaevakuasi menggunakan uji chi kuadrat. Karena jumlah sel dengan frekuensi harapan yang kurang dari 5 melebihi 20\%, maka digunakan uji alternatifnya yaitu uji Eksak Fisher. Penelitian ini menggunakan interval kepercayaan 95\%, hasil analisis dapat dikatakan signifikan apabila nilai $\mathrm{p}<0,05$.

Penelitian ini telah mendapat persetujuan dari Komisi Etik Penelitian Kesehatan Fakultas Kedokteran Universitas Padjadjaran (No:628/ UN6.C1.3.2/KEPK/PN/2016).

\section{Hasil}

Berdasarkan catatan rekam medis, terdapat 363 pasien mola hidatidosa selama periode 2010 2015, akan tetapi yang memenuhi kriteria inklusi penelitian berjumlah 81 pasien. Sebanyak 30 orang dieksklusi dari penelitian karena 11 orang mendapatkan kemoterapi profilaksis dan 19 pasien tidak dapat dikunjungi (lost to follow up). Pada akhirnya subjek yang diikutsertakan dalam penelitian ini berjumlah 51 orang, yang terdiri dari 44 penderita mola komplit dan 7 penderita mola parsial. Sebanyak 28 subjek berada pada kelompok karakteristik klinis risiko tinggi, sedangkan 23 pasien lainnya berada pada kelompok karakteristik klinis risiko rendah. Karakteristik subjek penelitian dapat dilihat pada tabel 1, berdasarkan penghitungan statistik dapat disimpulkan bahwa karakteristik pasien berupa usia, paritas, tipe mola dan indeks massa tubuh tidak memiliki perbedaan yang bermakna $(\mathrm{p}>0,05)$ sehingga layak untuk dibandingkan.

Tabel 2 menunjukkan karakteristik klinis pasien yang diklasifikasikan menjadi karakteristik klinis risiko tinggi dan risiko rendah.Berdasarkan analisis tabulasi silang antara karakteristik klinis dengan tipe mola menggunakan uji. Eksak Fisher, didapatkan nilai $\mathrm{p}>0,05$. Hal ini menunjukkan bahwa tidak terdapat perbedaan yang signifikan antara karakteristik klinis pasien mola hidatidosa komplit dengan karakteristik klinis pasien mola parsial

Selama rentang penelitian, terdapat sepuluh pasien yang tidak mengalami kehamilan. Dari total 41 yang mengalami kehamilan, 36 di antaranya memiliki luaran hamil normal. Luaran yang dianggap sebagai hamil normal adalah kehamilan yang berujung pada kelahiran janin yang masih memiliki kemungkinan hidup, berat janin $>500 \mathrm{~g}$, berakhir pada usia kehamilan $>20$ minggu. Dua pasien lainnya mendapatkan luaran hamil tidak normal berupa aborsi, kehamilan tidak normal lainnya yaitu kehamilan ektopik, pengulangan mola, dan blighted ovum tidak ditemukan. Data mengenai luaran kehamilan pasien pascaevakuasi mola disajikan pada tabel 3. Pasien yang hamil dianalisis luaran kehamilannya berdasarkan tipe mola menggunakan uji Eksak Fisher dan didapatkan nilai $p>0,05$. Hal ini menunjukkan tidak ada perbedaan luaran kehamilan yang signifikan antara pasien mola komplit dan mola.

Analisis tabulasi silang antara karakteristik klinis dengan luaran kehamilan pascaevakuasi dengan uji Eksak Fisher menghasilkan nilai signifikansi yang dapat dilihat pada tabel 4 . Karena didapatkan nilai $p>0,05$ maka dapat disimpulkan bahwa karakteristik klinis risiko tinggi yaitu: gambaran histopatologi proliferasi berlebih, besar uterus $\geq 20$ minggu, kadar $\beta$ $\mathrm{hCG}>100.000 \mathrm{mIU} / \mathrm{mL}$, dan terdapat kista lutein tidak memiliki hubungan yang signifikan pada luaran kehamilan bila dibandingkan dengan karakteristik klinis risiko rendah.

\section{Pembahasan}

Pada penelitian didapatkan bahwa karakteristik klinis risiko tinggi lebih banyak terdapat pada tipe mola komplit. Hal ini sesuai dengan literaturlainnya yang menyatakan bahwa mola 
Vanessa Natasha Harjito : Hubungan antara Karakteristik Klinis Pasien Mola Hidatidosa dengan Performa Reproduksi Pascaevakuasi di Rumah Sakit Hasan Sadikin Bandung

Tabel 1 Karakteristik Subjek Penelitian

\begin{tabular}{|c|c|c|c|}
\hline Karakteristik Pasien & $\begin{array}{c}\text { Kelompok karakteristik klinis } \\
\text { risiko tinggi } \\
\text { n (\%) }\end{array}$ & $\begin{array}{c}\text { Kelompok karakteristik klinis } \\
\text { risiko rendah } \\
\text { n (\%) }\end{array}$ & Nilai p* \\
\hline \multicolumn{4}{|l|}{ Usia (tahun) } \\
\hline Mean (SD) & $29,54(4,749)$ & $29,61(5,255)$ & 0,375 \\
\hline \multicolumn{4}{|l|}{ Paritas } \\
\hline 0 & $11(50 \%)$ & $11(50 \%)$ & 0,540 \\
\hline $1-4$ & $12(41,4 \%)$ & $17(58,6 \%)$ & \\
\hline \multicolumn{4}{|l|}{ Indeks Massa Tubuh } \\
\hline Median & 21,48 & 20,08 & 0,112 \\
\hline Rentang & $18,78-22,83$ & $18,29-22,94$ & \\
\hline \multicolumn{4}{|l|}{ Tipe mola } \\
\hline Mola komplit & $26(59,1 \%)$ & $18(40,9 \%)$ & 0,221 \\
\hline Mola parsial & $2(28,6 \%)$ & $5(71,4 \%)$ & \\
\hline \multicolumn{4}{|c|}{$\begin{array}{l}\text { (unitung berdasarkan uj1-t tidak berpasangan (untuk usia), uj1 ch1 kuadrat (untuk paritas), uj1 Mann-Whitney } \\
\text { (untuk indeks massa tubuh), uji Eksak Fisher (untuk tipe mola) }\end{array}$} \\
\hline Karakteristik Klinis & $\begin{array}{c}\text { Mola komplit } \\
\text { n (\%) }\end{array}$ & $\begin{array}{l}\text { Mola Parsial } \\
\text { n (\%) }\end{array}$ & Nilai p* \\
\hline \multicolumn{4}{|l|}{ Proliferasi berlebih } \\
\hline Ada & $5(83,3 \%)$ & $1(16,7 \%)$ & 1,000 \\
\hline Tidak ada & $39(86,7 \%)$ & $6(13,3 \%)$ & \\
\hline \multicolumn{4}{|l|}{ Besar uterus } \\
\hline$\geq 20$ minggu & $14(100 \%)$ & $0(0 \%)$ & 0,169 \\
\hline$<20$ minggu & $30(81,1 \%)$ & $7(18,9 \%)$ & \\
\hline \multicolumn{4}{|l|}{ Kadar $\beta$-hCG } \\
\hline$>100.000 \mathrm{mIU} / \mathrm{mL}$ & $23(92,0 \%)$ & $2(8,0 \%)$ & 0,419 \\
\hline$<100.000 \mathrm{mIU} / \mathrm{mL}$ & $21(80,8 \%)$ & $5(19,2 \%)$ & \\
\hline \multicolumn{4}{|l|}{ Kista lutein } \\
\hline Ada & $4(66,7 \%)$ & $2(33,3 \%)$ & 0,186 \\
\hline Tidak ada & $40(88,9 \%)$ & $5(11,1 \%)$ & \\
\hline
\end{tabular}

Tabel 3 Luaran Kehamilan Pasien Mola Hidatidosa Komplit dan Parsial

\begin{tabular}{cccc}
\hline Tipe Mola Hidatidosa & $\begin{array}{c}\text { Hamil Tidak Normal } \\
\text { n (\%) }\end{array}$ & $\begin{array}{c}\text { Hamil Normal } \\
\text { n (\%) }\end{array}$ & Nilai p* \\
\hline Mola komplit & $2(5,6 \%)$ & $34(94,4 \%)$ & 1,000 \\
Mola parsial & $0(0 \%)$ & $5(100 \%)$ & \\
Total & $2(4,9 \%)$ & $39(95,1 \%)$ & \\
\hline \% & & &
\end{tabular}


Tabel 4 Luaran Kehamilan berdasarkan Karakteristik Klinis Pasien Mola Hidatidosa

\begin{tabular}{cccc}
\hline Karakteristik Klinis & $\begin{array}{c}\text { Hamil Normal } \\
\text { n (\%) }\end{array}$ & $\begin{array}{c}\text { Hamil tidak normal } \\
\text { n (\%) }\end{array}$ & Nilai p* \\
\hline Proliferasi berlebih & & & \\
Ada & $3(75 \%)$ & $1(25 \%)$ & 0,188 \\
Tidak ada & $36(97,3 \%)$ & $1(2,7 \%)$ & \\
$\begin{array}{c}\text { Besar uterus } \\
\geq 20 \text { minggu }\end{array}$ & $12(100 \%)$ & $0(0 \%)$ & 1,000 \\
$<20$ minggu & $27(93,1 \%)$ & $2(6,9 \%)$ & \\
$\begin{array}{l}\text { Kadar } \beta \text {-hCG } \\
>100.000 \mathrm{mIU} / \mathrm{mL}\end{array}$ & $18(94,7 \%)$ & $1(5,3 \%)$ & 1,000 \\
$<100.000 \mathrm{mIU} / \mathrm{mL}$ & $21(95,5 \%)$ & $1(4,5 \%)$ & \\
Kista lutein & $6(100 \%)$ & $0(0 \%)$ & 1,000 \\
Ada & $33(94,3 \%)$ & $2,(5,7 \%)$ & \\
Tidak ada & & & \\
\%dihitung berdasarkan uj1 Eksak Fisher & & & \\
\end{tabular}

komplit lebih sering memiliki karakteristik yang menunjukkan risiko keganasan. ${ }^{14}$ Namun demikian, berdasarkan uji statistiktidak terdapat perbedaan yang signifikan antara karakteristik klinis pasien mola hidatidosa komplit dengan karakteristik klinis pasien mola parsial.

Dari 51 pasien yang menjadi subjek penelitian, terdapat 10 pasien yang tidak mengalami kehamilan kembali sehingga tingkat infertilitas dalam penelitian inibernilai 19,6\%. Angka ini jauh lebih besar bila dibandingkan dengan penelitian lainnya yang menyatakan tingkat infertilitas senilai 8,9\%.16 Perlu dilakukan penelitian lebih lanjut untuk menginvestigasi penyebab ketidakhamilan ini, karena terdapat penelitian lain yang menyimpulkan bahwa tingkat fertilitas pascamola tidak memiliki perbedaan dengan ibu yang hamil normal. ${ }^{17}$ Kemungkinan besar penyebab tingginya persentase ketidakhamilan ini adalah rasa takut pasien untuk mencoba hamil kembali, bukan karena adanya gangguan pada fungsi sistem reproduksi. ${ }^{7}$

Berdasarkan hasil uji Eksak Fisher pada pasien yang memiliki luaran kehamilan, dapat disimpulkan bahwa tidak ada perbedaan luaran kehamilan yang signifikan antara pasien mola komplit dan mola parsial. Persentase total luaran kehamilan normal pascamola sebesar $95 \%$, temuan ini sesuai dengan penelitian yang menyatakan pasien mola hidatidosa masih mungkin untuk memiliki fungsi reproduksi yang normal di masa yang akan datang, dengan temuan sebanyak $2 \%$ penderita mola hidatidosa yang memperoleh kehamilan tidak normal. ${ }^{11}$ Penelitian lainnya menyatakan bahwa luaran kehamilan pascamola hidatidosa dapat menyerupai kehamilan pada populasi normal tanpa melihat tipe mola yang diderita. ${ }^{18-20}$

Beberapa penelitian menyatakan bahwa risiko pasien untuk mengalami kehamilan mola untuk kedua kalinya meningkat sebanyak 10-20 kali lipat bagi pasien dibanding populasi normal yaitu menjadi $1,8 \%{ }^{8,18,20}$ Namun pada penelitian ini, pasien yang mengalami pengulangan mola tidak ditemukan, luaran kehamilan tidak normal yang ditemukan hanya berupa aborsi. Temuan ini serupa dengan penelitian yang dilakukan di RSHS sebelumnya yang tidak menemukan pengulangan mola. ${ }^{17}$ Fenomena tidak adanya pengulangan mola ini mungkin disebabkan karena adanyaperbedaan karakteristik pasien yang diteliti, misalnya faktor ras atau genetik. Untuk memastikan penyebab fenomena ini perlu dilakukan penelitian lebih lanjut.

Berdasarkan hasil penelitian dapat disimpulkan bahwa karakteristik klinis risiko tinggi yaitu: gambaran histopatologi proliferasi berlebih, besar uterus $\geq 20$ minggu, kadar $\beta$ hCG $>100.000 \mathrm{mIU} / \mathrm{mL}$, dan terdapat kista luteinpraevakuasi tidak memiliki hubungan dengan luaran kehamilan pascamola. Berdasarkan temuan ini dapat diberikan konseling kepada penderita mola dengan karakteristik klinis risiko tinggi agar tidak perlu khawatir tidak dapat hamil kembali dan meyakinkan penderita bahwa dirinya dapat mengalami kehamilan yang normal pascakehamilan mola. Hasil penelitian ini diharapkan dapat memperkaya pengetahuan mengenai kasus mola hidatidosa. Hasil penelitian ini juga dapat digunakan sebagai data tambahan untuk penelitian bertopik mola hidatidosa selanjutnya. Selain itu, dengan mengetahui 
gambaran performa reproduksi pascaevakuasi mola hidatidosa serta hubungannya dengan karakteristik klinis pasien dapat membantu klinisi dalam pertimbangan untuk mengambil tindakan lanjutan terhadap pasien.

Keterbatasan dalam penelitian ini adalah kemungkinan adanya bias informasi karena pengambilan data dilakukan secara retrospektif sehingga dapat menimbulkan recall bias dan sebagian data merupakan data sekunder.Selain itu terdapat perbedaan kualitas data antara informasi yang diperoleh melalui wawancara langsung dengan yang diperoleh via telepon. Kendala lainnya adalah sulitnya menghubungi pasien karena data nomor telepon dan alamat pasien tidak lengkap, ataupun ketidakmampuan dalam menjangkau wilayah tempat tinggal pasien. Keterbatasan waktu penelitian juga menjadi kendala dalam penelitian ini.

Saran untuk penelitian selanjutnya adalah sebaiknya menggunakan jumlah sampel yang lebih besar agar mendapatkan hasilyang lebih akurat. Pendataan pada saat pasien berobat sebaiknya dilakukan dengan lebih teliti dan lengkap agar memudahkan dalam menghubungi pasien saat penelitian selanjutnya. Selain itu diperlukan penelitian lebih lanjut untuk melihat hubungan antara karakteristik klinis risiko tinggi dengan tingkat infertilitas pascamola, pada penelitian ini tidak dilakukan karena jumlah sampel yang dimiliki tidak memadai.

\section{Daftar Pustaka}

1. Fitriani R. Mola Hidatidosa. Jurnal Kesehatan Fakultas Kedokteran UIN Alauddin Makassar. 2009. 2:1-6.

2. Tidy J, Hancock B. The Management of Gestational Trophoblastic Disease. RCOG Greentop. 2010(38):1-11.

3. Fatima M, Kasi PM, Baloch SN, Kassi M, Marri SM, Kassi M. Incidence, management, and outcome of molar pregnancies at a tertiary care hospital in Quetta, Pakistan. ISRN obstetrics and gynecology. 2011 (diunduh 19 September 2016). Tersedia dari: https://www. hindawi.com/

4. Khaza'leh F, Haloub K, Freij M. Recurrent Hydatidiform Molar Pregnancy: A Case Report of 5 Consecutive Molar Pregnancies Complicated by HELLP and DIC, and Review of Literature. Open Journal of Obstetrics and Gynecology. 2015;5(12):731.

5. Paputungan TV, Wagey FW, Lengkong RA. Profil penderita mola hidatidosa di RSUP Prof. Dr. RD Kandou Manado. e-CliniC. 2016;4(1).
6. Syafii, Aprianti S, Hardjoeno. Kadar $\beta$-hCG Penderita Mola Hidatidosa Sebelum dan Sesudah Kuretase. Indonesian Journal of Clinical Pathology and Medical Laboratory. 2006;13(1):1-3.

7. Petersen RW, Ung K, Holland C, Quinlivan JA. The impact of molar pregnancy on psychological symptomatology, sexual function, and quality of life. Gynecologic Oncology. 2005;97(2):535-42.

8. Lurain JR. Gestational trophoblastic disease I: epidemiology, pathology, clinical presentation and diagnosis of gestational trophoblastic disease, and management of hydatidiform mole. American journal of obstetrics and gynecology. 2010;203(6):5319.

9. Savage P, Sita-Lumsden A, Dickson S, Iyer R, Everard J, Coleman R, et al. The relationship of maternal age to molar pregnancy incidence, risks for chemotherapy and subsequent pregnancy outcome. Journal of Obstetrics and Gynaecology. 2013;33(4):406-11.

10. Eagles N, Sebire N, Short D, Savage P, Seckl M, Fisher R. Risk of recurrent molar pregnancies following complete and partial hydatidiform moles. Human Reproduction. 2015:169.

11. Sebire N, Fisher R, Foskett M, Rees H, Seckl M, Newlands E. Risk of recurrent hydatidiform mole and subsequent pregnancy outcome following complete or partial hydatidiform molar pregnancy. BJOG: An International Journal of Obstetrics \& Gynaecology. 2003;110(1):22-6.

12. Hidayat YM, Gandamihardja S, Krisnadi SR. Hubungan Kadar $\beta H C G$ Praevakuasi, Gambaran Histopatologi, dan Kista Lutein dengan Performa $\beta$ HCG pada Penderita Mola Hidatidosa yang Berkembang Menjadi PTG dan Kembali Normal. Majalah Kedokteran Bandung. 2014;46(4):247-52.

13. Triana A, Hidayat YM, Gandamihardja S, Bayuaji H. Performa Reproduksi Pasca Evakuasi Mola Hidatidosa Komplit pada Kelompok Risiko Tinggi dan Risiko Rendah di RSUP Dr. Hasan Sadikin Bandung. [Tesis] Bandung: Universitas Padjadjaran; 2014.

14. Mangili G, Garavaglia E, Cavoretto $P$, Gentile C, Scarfone G, Rabaiotti E. Clinical presentation of hydatidiform mole in northern Italy: has it changed in the last 20 years? American journal of obstetrics and gynecology. 2008;198(3):302. e1-. e4.

15. Almasi A, Almassinokiani F, Akbari P. Frequency of molar pregnancies in health care centers of Tehran, Iran. Journal of reproduction \& infertility. 2014;15(3):157. 
16. Pastorfide GB, Goldstein DP. Pregnancy after hydatidiform mole. Obstetrics \& Gynecology. 1973;42(1):67-70.

17. Martaadisoebrata D, WahyudiAP, Ghazali MF. Reproductive Function Post Hydatidiform Mole. Obstetric and Gynecologic Department Hasan Sadikin General Hospital/FKUP Bandung. 2015 (diunduh 19 November 2016). Tersedia dari: https://www.scribd. com/document/281346820/ReproductiveFunction-Post-Hydatidiform-Mole.

18. Berkowitz RS, Goldstein DP. Current management of gestational trophoblastic diseases. Gynecologiconcology. 2009;112(3):654-62.
19. Garrett LA, Garner EI, Feltmate CM, Goldstein DP, Berkowitz RS. Subsequent pregnancy outcomes in patients with molar pregnancy and persistent gestational trophoblastic neoplasia. Obstetrical \& Gynecological Survey. 2008;63(11):704-5.

20. Vargas R, Barroilhet LM, Esselen K, Diver E, Bernstein M, Goldstein DP, et al. Subsequent pregnancy outcomes after complete and partial molar pregnancy, recurrent molar pregnancy, and gestational trophoblastic neoplasia: an update from the New England Trophoblastic Disease Center. The Journal of reproductive medicine. 2013;59(5-6):188-94. 